\title{
Stem Canker on Cyclocarya paliurus Is Caused by Botryosphaeria dothidea
}

\author{
Xiang-rong Zheng, Mao-jiao Zhang, Xu-lan Shang, Sheng-zuo Fang, and Feng-mao Chen ${ }^{\dagger}$ \\ Collaborative Innovation Center of Sustainable Forestry in Southern China, College of Forestry, Nanjing Forestry University, \\ Nanjing, Jiangsu 210037, China
}

\begin{abstract}
Cyclocarya paliurus, an important endangered plant in China, has considerable medicinal, timber, and horticultural value. However, little is known about diseases that affect its health. In recent years, stem canker diseases on C. paliurus have been observed frequently in newly established nurseries in Jiangsu Province, China. Symptomatic trees showed elliptical, sunken lesions on the bark, with internal discoloration, leading to enlarging cankers with delineated margins. Pathogenicity tests

cause stem canker on $C$. paliurus. Through combined morphological observation and DNA sequences of ITS region, $\beta$-tubulin, and translation elongation factor $1-\alpha$ genes, the pathogen was identified as Botryosphaeria dothidea. Multigene maximum likelihood and maximum parsimony phylogenetic analyses further supported the identification of the pathogen. To our knowledge, this is the first report of $B$. dothidea causing stem canker on C. paliurus in China.
\end{abstract} with fungi isolated from symptomatic samples reproduced typical canker symptoms on both detached branches and potted plants of C. paliurus. Moreover, conidia from pycnidia of isolate ZB-23 could also
Keywords: Botryosphaeria dothidea, Cyclocarya paliurus, first report, pathogen detection, stem canker
Cyclocarya paliurus (Batal.) Iljinskaja, a Chinese native plant, belongs to the Juglandaceae family and is the sole species in the genus Cyclocarya (Xie et al. 2010). The bark and leaves of $C$. paliurus were extensively used for making officinal tea in ancient China (Xie and Li 2001). C. paliurus, widely distributed in middle and lower reaches of the Yangtze River, was reported to have high potential as a new food ingredient in 2013 (Wang et al. 2017). Increasing attention has been drawn to the use of this plant for developing functional food because of its unique biological activities, such as hypolipidemic activity (Kurihara et al. 2003a), antihypertensive activity (Kurihara et al. 2003a), antioxidant activity (Dong et al. 2007; Xie et al. 2010, 2012), enhancement of mental efficiency ( $\mathrm{Li}$ et al. 2000), and hypoglycemic activity (Kurihara et al. 2003b; Xie et al. 2006).

Current research on C. paliurus has been focused on breeding and identification of active chemical substances. However, little information regarding diseases affecting this plant is available. From 2016 to 2018, a severe stem canker of young $C$. paliurus trees ( 3 to 5 years old) was observed, with $>35 \%$ incidence ( 300 trees were calculated), in a newly established nursery at Baima experiment and research farm (Baima), Jiangsu Province, China. From autumn 2017 to spring 2018, similar symptoms were found in Shitai County, Anhui Province, with an incidence of $>25 \%$ (120 trees were calculated).

The ascomycete genus Botryosphaeria includes significant phytopathogens with a broad global distribution (Burgess et al. 2005; Slippers et al. 2005; van Niekerk et al. 2004; Zhai et al. 2014). Species in this genus cause stem cankers, branch and tip dieback, fruit rots, or the death of the host plant and do not show any host preference (Slippers and Wingfield 2007). Botryosphaeria dothidea (Moug. ex Fr.) Ces. \& De Not. is the type species of this genus (Marsberg et al. 2017). There was much confusion about the classification and identification of $B$. dothidea, because many morphologically similar specimens reported to belong to other species had been reported to represent B. dothidea (Marsberg et al. 2017). In order to solve the

${ }^{\dagger}$ Corresponding author: F.-M. Chen; cfengmao@njfu.edu.cn

Funding: This study was financially supported by the National Key R \& D Program of China grant 2017YFD0600104.

The author(s) declare no conflict of interest.

Accepted for publication 4 November 2019

(C) 2020 The American Phytopathological Society problem, Barr (1972) designated Botryosphaeria dothidea (Moug. ex Fr.) Ces. \& De Not. as the lectotype species for the genus, and the epitypification of $B$. dothidea largely resolved the taxonomic confusion (Slippers et al. 2004).

The teleomorphs of Botryosphaeria spp. are rarely observed in culture, whereas anamorphs are common (van Niekerk et al. 2004). Therefore, the morphological taxonomy and identification of Botryosphaeria spp. are based mainly on characteristics observed in the asexual phase (Slippers et al. 2005). Morphological features of Botryosphaeria spp. differ between isolates and overlap with those of other species in the Botryosphaeriaceae family; thus, they are no longer routinely used for identification (Marsberg et al. 2017; Zhou et al. 2015). Consequently, the identification of Botryosphaeria spp. should be based on phenotypical features combined with molecular data, wherein the internal transcribed spacer region (ITS), translation elongation factor 1 - $\alpha$ (TEF), and $\beta$-tubulin (BT) genes are the most reliable and powerful in current mycological taxonomy for accurate identification (Lynch et al. 2013; Marincowitz et al. 2008; Pavlic et al. 2009; Pérez et al. 2010).

To our knowledge, there has been no investigation of Botryosphaeria spp. causing $C$. paliurus stem canker disease in China. Therefore, the objective of this research was to identify the causal agent of stem canker disease of $C$. paliurus by means of morphological studies, molecular characterization, multilocus phylogeny, and pathogenicity tests.

\section{Materials and Methods}

Field survey, fungal isolation, and morphological observation. Field surveys were conducted from October 2017 to June 2018 in five newly established $C$. paliurus nurseries located in Baima, Nanjing, China. In total, 78 diseased samples were collected, consisting of plants bearing typical cankers. The samples were then transported to the laboratory for further analysis. The outer bark was carefully removed with a sterile scalpel. Tissue at the margins of cankers was cut into $0.5 \mathrm{~cm}^{2}$ pieces, sterilized in $75 \%$ (vol/vol) ethanol for $45 \mathrm{~s}$, and washed three times with sterilized water, then cultured on potato dextrose agar (PDA) containing ampicillin $(100 \mu \mathrm{g} / \mathrm{ml})$ after drying on sterile absorbent paper. The plates were incubated at $25^{\circ} \mathrm{C}\left( \pm 1^{\circ} \mathrm{C}\right)$ in the dark until growth could be detected. Pure cultures were obtained by transferring mycelial tips onto fresh PDA and serially diluting monospores.

Based on morphological characteristics, fungal species were first identified to the genus level (Moral et al. 2017). The phenotypical features of the anamorphs, including shape, size, color, wall thickness, and septation of conidia, were recorded from the colonies 
developed in vitro. For morphological identification, single conidial cultures were obtained by serially diluting monospores ( $\mathrm{Li}$ et al. 2007), which were transferred to PDA for 10 days at $25^{\circ} \mathrm{C}$. In order to induce sporulation, an inoculation needle was used to scratch the aerial mycelia of the same isolates, which were then irradiated under near ultraviolet light $(365 \mathrm{~nm}$ ) for 2 months (Zhai et al. 2014). The experiment was performed twice.

Fungal structures were captured with a digital camera. Conidial morphology was observed with a light microscope at $100 \times$ magnification; the length and width of 80 conidia per isolate were determined. Characteristics of mycelia (color, texture, density, and zonation) were also recorded after 1 week of incubation at $25^{\circ} \mathrm{C}$.

DNA extraction and PCR amplification. Genomic DNA of all isolates was extracted via the CTAB method as described by Damm et al. (2008). The ITS region, TEF, and BT genes were amplified and sequenced with the primer pairs ITS1+ITS4 (White et al. 1990), EF1728F+EF1-986R (Carbone and Linda 1999), and Bt2a+Bt2b (Glass and Donaldson 1995), respectively. Amplification was performed in a 50- $\mu$ l volume containing $4 \mu \mathrm{l}$ (100 ng) of DNA template, $2 \mu \mathrm{l}$ of each primer $(10 \mathrm{pmol} / \mu \mathrm{l}), 25 \mu \mathrm{l}$ Taq DNA solution, and $17 \mu \mathrm{l}$ double-distilled $\mathrm{H}_{2} \mathrm{O}$ with a thermal cycler, under the conditions listed in Table 1. PCR products were electrophoresed on $1.5 \%$ agarose gel. DNA sequencing was performed at the Nanjing Genscript Biological Technology Company Limited (Nanjing, China). Sequences derived in this study were deposited in GenBank. GenBank accession numbers relating to the isolates are listed in Table 2.

Phylogenetic analysis. Botryosphaeria spp. ITS, BT, and TEF sequences, including those representing ex-type strains, with high similarity to our sequences were selected from GenBank via BLAST. Nucleotide sequences were edited with BioEdit version 7.0.5 (https:// web.archive.org/web/20191129050357/http://www.mbio.ncsu.edu/ BioEdit/bioedit.html) and aligned with Clustal $\mathrm{X}$ version 1.83 (Thompson et al. 1997). Gaps in the alignment were treated as a fifth character, and all of the characters were unordered and had equal weight (Salemi and Vandamme 2003). Multilocus phylogenetic analysis was conducted with two independent optimality search criteria, maximum likelihood (ML) and maximum parsimony (MP), in MEGA 6 (Tamura et al. 2013). The ML analysis used the GTR+G+I model, and branch stability was determined by 1,000 bootstrap replicates. MP analyses involved heuristic searches with 1,000 random sequence additions via the tree-bisection-reconnection algorithm. Bootstrap analyses with 1,000 replicates were used to estimate clade support. The tree length, consistency index (CI), and retention index (RI) were calculated. Meanwhile, Tiarosporella graminis (strain CBS 118718; GenBank ITS $=$ KC769962, BT $=$ KF531808, TEF $=$ KF531807) was selected as an outgroup.

Pathogenicity test on detached branches. Three representative isolates (ZB-8, ZB-23, and ZB-69) were grown on PDA at $25^{\circ} \mathrm{C}$ for 5 days before inoculation. In March 2018, 2-year-old detached shoots (13 to $17 \mathrm{~cm}$ long and 0.7 to $1.3 \mathrm{~cm}$ in diameter) were collected from $C$. paliurus trees grown in Baima (Jiangsu Province, China). The branch segment was sealed at both ends with melted paraffin to reduce desiccation and disinfected with $70 \%$ ethanol before inoculation. One wound $(0.15 \mathrm{~cm}$ in diameter and $0.2 \mathrm{~cm}$ in depth) was made on each branch segment by poking with a sterilized needle. A 1-cm diameter mycelial disc from the growing margin of the colony was placed on the wound, and negative control branches were treated with a PDA plug, as described by Zhai et al. (2014). Five detached branches were treated as one replicate, and three replicates were treated for treatment and control. The experiment was repeated twice. All inoculated and control branch segments were kept in a growth chamber at $27^{\circ} \mathrm{C}$ with $100 \% \mathrm{RH}$. For each branch, evaluation of symptoms and disease incidence were obtained according to the methods of Zhai et al. (2014).

Pathogenicity test on intact plants. Three representative isolates (ZB-8, ZB-23, and ZB-69) were inoculated to determine pathogenicity. Three-year-old potted, asymptomatic $C$. paliurus plants were obtained from Baima experimental base for Nanjing Forestry University. The potted plants were inoculated under natural conditions with mycelium plugs, as described for detached shoots, $120 \mathrm{~cm}$ above the soil level; control trees were treated with a PDA plug. The inoculated sites were covered with strips of plastic film sterilized by ultraviolet light to maintain humidity, and the plastic film was removed at 10 days after inoculation. Five potted plants were treated as one replicate, and three replicates were treated for treatment and control. The experiment was conducted twice. Evaluation of symptoms was recorded every 5 days.

Pathogenicity of conidia collected from pycnidia. In order to verify the hypothesis that the pycnidia of Botryosphaeriaceae species can be used as primary inoculum, conidia of isolate ZB-23, which were produced on the surface of an inoculated branch, were collected in $30 \mathrm{ml}$ of distilled water in a sterile 50-ml tube and shaken until the conidia were released into the water. The spore suspension was filtered through filter cloth to remove impurities, as described by Zhou et al. (2015).

To determine the pathogenicity of conidia on detached branches and intact plants of $C$. paliurus, the collected conidial suspension was diluted to $10^{4}$ conidia/ $/ \mathrm{ml}^{-1}$. For the first experiment, $20 \mu \mathrm{l}$ of conidial suspension or sterile distilled water (as control) was placed in the wound $(0.15 \mathrm{~cm}$ in diameter and $0.2 \mathrm{~cm}$ in depth) of branch segments prepared as above. All inoculated and control branch segments were kept in a growth chamber at $27^{\circ} \mathrm{C}$ with $100 \% \mathrm{RH}$. For the second experiment, $20 \mu \mathrm{l}$ of conidial suspension or sterile distilled water (as control) was placed in a wound made on potted plants prepared as above under natural conditions. All inoculated sites were covered with plastic film as mentioned above. Evaluation of symptoms and disease incidence was performed as described above. For these two experiments, five detached branches or intact plants were treated as one replicate, and three replicates were treated for each treatment and control. The entire experiment was repeated twice.

To complete Koch's postulate, reisolation was conducted with fungal material from the margins of inoculated branches that showed the same disease symptoms observed in Baima previously. Morphological characteristics and the sequence analysis of the ITS region, TEF, and BT genes were used to confirm whether the reisolated fungi were the same as the original inoculated isolate.

Statistical analyses. For each pathogenicity test, differences in canker length (in millimeters) and disease incidence (percentage) among isolates were determined via ANOVA in SPSS 22.0 software. When ANOVA showed significant differences, the treatment means were compared according to Tukey's honestly significant difference test $(P=0.05)$.

\section{Results}

Disease development in nature, collection of fungal isolates, and morphology. Typical symptoms appeared as stem cankers (Fig. 1A, H, and I) with a clear delineation from the stem (Fig. 1I), usually originating from small, necrotic lesions that formed on the

Table 1. Sequences of primer sets targeted to the internal transcribed spacer (ITS) region, $\beta$-tubulin (BT) gene, and translation elongation factor 1- $\alpha$ (TEF) gene

\begin{tabular}{|c|c|c|c|}
\hline Primer code & Sequence $\left(5^{\prime}-3^{\prime}\right)$ & Target & PCR conditions \\
\hline ITS1 & TCCGTAGGTGAACCTGCG & \multirow[t]{2}{*}{ rDNA-ITS } & \multirow{2}{*}{$\begin{array}{l}\text { Denaturation for } 3 \mathrm{~min} \text { at } 94^{\circ} \mathrm{C} \text {, followed by } 30 \text { cycles; } 30 \mathrm{~s} \text { at } 94^{\circ} \mathrm{C}, 30 \mathrm{~s} \text { at } \\
55^{\circ} \mathrm{C}, 30 \mathrm{~s} \text { at } 72^{\circ} \mathrm{C} \text {, and a final extension of } 10 \mathrm{~min} \text { at } 72^{\circ} \mathrm{C}\end{array}$} \\
\hline ITS4 & TCCTCCGCTTATTGATAT & & \\
\hline $\mathrm{Bt} 2 \mathrm{a}$ & GGTAACCAAATCGGTGCTGCTTTC & \multirow[t]{2}{*}{ BT } & \multirow{2}{*}{$\begin{array}{l}\text { Denaturation for } 3 \mathrm{~min} \text { at } 94^{\circ} \mathrm{C} \text {, followed by } 30 \text { cycles; } 30 \mathrm{~s} \text { at } 94^{\circ} \mathrm{C}, 30 \mathrm{~s} \text { at } \\
60^{\circ} \mathrm{C}, 30 \mathrm{~s} \text { at } 72^{\circ} \mathrm{C} \text {, and a final extension of } 10 \mathrm{~min} \text { at } 72^{\circ} \mathrm{C}\end{array}$} \\
\hline $\mathrm{Bt} 2 \mathrm{~b}$ & ACCCTCAGTGTAGTGACCCTTGGC & & \\
\hline EF1-728F & CATCGAGAAGTTCGAGAAGG & \multirow[t]{2}{*}{ TEF } & \multirow{2}{*}{$\begin{array}{l}\text { Denaturation for } 3 \mathrm{~min} \text { at } 94^{\circ} \mathrm{C} \text {, followed by } 30 \text { cycles; } 30 \mathrm{~s} \text { at } 94^{\circ} \mathrm{C}, 30 \mathrm{~s} \text { at } \\
60^{\circ} \mathrm{C}, 30 \mathrm{~s} \text { at } 72^{\circ} \mathrm{C} \text {, and a final extension of } 10 \mathrm{~min} \text { at } 72^{\circ} \mathrm{C}\end{array}$} \\
\hline EF1-986R & TACTTGAAGGAACCCTTACC & & \\
\hline
\end{tabular}


bark (Fig. 1C) and then enlarged to form large, sunken, regular- or irregular-shaped cankers (Fig. 1E). Under unsuitable growing environments, the cankers coalesced, forming large areas of withered tissue, which turned brown or black (Fig. 1A and B). The cortex of the infected branch is rotten and necrotic, and the xylem is blackened, from the transverse section view (Fig. 1K). Surface sterilization and fragmentation of the pathological tissue into small pieces $\left(0.5 \mathrm{~cm}^{2}\right)$ before plating allowed the consistent isolation of one fungus with uniform morphological characteristics in culture on PDA (Fig. 2A and B). In total, 89 fungal isolates from typical cankers were collected. The colonies were initially white and became dark gray 7 days after incubation, and the aerial hyphae were short and thick with an irregular colony margin (Fig. 2A). The underneath of colonies was first white and turned black with age (Fig. 2B). A few

Table 2. Descriptions and sequence accession numbers obtained from GenBank of the Botryosphaeria spp. used in the phylogenetic study

\begin{tabular}{|c|c|c|c|c|c|c|}
\hline \multirow[b]{2}{*}{ Species, isolate ${ }^{x}$} & \multirow[b]{2}{*}{ Host } & \multirow[b]{2}{*}{ Location } & \multirow[b]{2}{*}{ Collector } & \multicolumn{3}{|c|}{ GenBank accession number $^{y}$} \\
\hline & & & & ITS & BT & TEF \\
\hline \multicolumn{7}{|c|}{ Botryosphaeria dothidea } \\
\hline BOO046 & Olea europaea & Spain & J. Moral & GU292626 & GU292738 & GU292682 \\
\hline CBS 110302 & Vitis vinifera & Portugal & A.J.L. Phillips & AY259092 & EU673106 & AY573218 \\
\hline CERC1976 & Juglans regia $\mathrm{L}$. & China & S.F. Chen & KR261706 & KR261730 & KR261718 \\
\hline CLASL1 & Umbellularia californica & USA, California & F.P. Trouillas & KX357176 & KX357153 & KX357199 \\
\hline CMW39308 & Sequoiadendron giganteum & Serbia & N. Keca & KF575008 & KF575104 & KF575040 \\
\hline CMW7780 & Fraxinus excelsior & Molinizza, Switzerland & B. Slippers & AY236947 & AY236925 & AY236896 \\
\hline CMW7999 & Ostrya $\mathrm{sp}$. & Crocifisso, Switzerland & B. Slippers & AY236948 & AY236926 & AY236897 \\
\hline CMW8000 & Prunus sp. & Crocifisso, Switzerland & B. Slippers & AY236949 & AY236927 & AY236898 \\
\hline CMW9075 & Prunus nigra & New Zealand & G.J. Samuels & AY236950 & AY236928 & AY236899 \\
\hline L9E2 & U. californica & USA, California & F.P. Trouillas & KX357172 & KX357149 & KX357195 \\
\hline N14 & Psidium guajava & Brazil & A.F. Nogueira Júnior & KJ863654 & KJ863647 & KM349761 \\
\hline $\mathrm{ZB}-8^{\mathrm{z}}$ & Cyclocarya paliurus & China & X.R. Zheng & MH715239 & MH726145 & MH726156 \\
\hline ZB-15 & C. paliurus & China & X.R. Zheng & MH715242 & MH726148 & MH726159 \\
\hline $\mathrm{ZB}-23^{\mathrm{z}}$ & C. paliurus & China & X.R. Zheng & MH715240 & MH726146 & MH726157 \\
\hline ZB-27 & C. paliurus & China & X.R. Zheng & MH715243 & MH726149 & MH726160 \\
\hline ZB-33 & C. paliurus & China & X.R. Zheng & MH715244 & MH726150 & MH726161 \\
\hline ZB-36 & C. paliurus & China & X.R. Zheng & MH715245 & MH726151 & MH726162 \\
\hline ZB-45 & C. paliurus & China & X.R. Zheng & MH715246 & MH726152 & MH726163 \\
\hline ZB-56 & C. paliurus & China & X.R. Zheng & MH715247 & MH726153 & MH726164 \\
\hline ZB-59 & C. paliurus & China & X.R. Zheng & MH715248 & MH726154 & MH726165 \\
\hline $\mathrm{ZB}-69^{\mathrm{z}}$ & C. paliurus & China & X.R. Zheng & MH715241 & MH726147 & MH726158 \\
\hline ZB-77 & C. paliurus & China & X.R. Zheng & МH715249 & MH726155 & MH726166 \\
\hline ZJ-B1 & Vaccinium corymbosum & China & C.N. Xu & KP183178 & KP183135 & KP183216 \\
\hline \multicolumn{7}{|l|}{ Botryosphaeria ribis } \\
\hline CMW7772 & Ribes sp. & New York & B. Slippers/G. Hudler & AY236935 & AY236906 & AY236877 \\
\hline CMW7773 & Ribes sp. & New York & B. Slippers/G. Hudler & AY236936 & AY236907 & AY236878 \\
\hline \multicolumn{7}{|l|}{ Botryosphaeria obtusa } \\
\hline CMW7774 & Ribes sp. & New York, USA & B. Slippers/G. Hudler & AY236953 & AY236931 & AY236902 \\
\hline CMW7775 & Ribes sp. & New York, USA & B. Slippers/G. Hudler & AY236954 & AY236932 & AY236903 \\
\hline \multicolumn{7}{|l|}{ Botryosphaeria lutea } \\
\hline CMW9076 & Malus $\times$ domestica & New Zealand & S.R. Pennycook & AY236946 & AY236922 & AY236893 \\
\hline \multicolumn{7}{|c|}{ Botryosphaeria rhodina } \\
\hline CMW9074 & Pinus sp. & Mexico & T. Burgess & AY236952 & AY236930 & AY236901 \\
\hline CMW10130 & Vitex doniana & Uganda & J. Roux & AY236951 & AY236929 & AY236900 \\
\hline \multicolumn{7}{|l|}{ Botryosphaeria parva } \\
\hline CMW9077 & Actinidia deliciosa & New Zealand & S.R. Pennycook & AY236939 & AY236913 & AY236884 \\
\hline CMW9081 & Populus nigra & New Zealand & G.J. Samuels & AY236943 & AY236917 & AY236888 \\
\hline \multicolumn{7}{|c|}{ Botryosphaeria stevensii } \\
\hline CMW7060 & F. excelsior & Netherlands & H.A. van der Aa & AY236955 & AY236933 & AY236904 \\
\hline \multicolumn{7}{|l|}{ Botryosphaeria corticis } \\
\hline CBS 119047 & Vaccinium corymbosum & USA & A.J.L. Phillips & DQ299245 & EU673107 & EU017539 \\
\hline ATCC 22927 & Vaccinium sp. & North Carolina, USA & R.D. Millholland & DQ299247 & EU673108 & EU673291 \\
\hline \multicolumn{7}{|l|}{ Botryosphaeria agaves } \\
\hline CBS 133992 & Agave sp. & Thailand & R. Phookamsak & JX646791 & JX646841 & JX646856 \\
\hline MFLUCC 10-0051 & Agave sp. & Thailand & Putarak Chomnunti & JX646790 & JX646840 & JX646855 \\
\hline \multicolumn{7}{|c|}{ Botryosphaeria australis } \\
\hline CMW9072 & Acacia sp. & Australia & B. Slippers & AY339260 & AY339252 & AY339268 \\
\hline \multicolumn{7}{|l|}{ Botryosphaeria ramosa } \\
\hline CMW 26167 & Eucalyptus camaldulensis & Australia & T.I. Burgess & EU144055 & KF766132 & EU144070 \\
\hline \multicolumn{7}{|l|}{ Tiarosporella graminis } \\
\hline CBS 118718 & Nestlera sp. & South Africa & B. Sutton & KC769962 & KF531808 & KF531807 \\
\hline
\end{tabular}

${ }^{\mathrm{x}}$ Isolate numbers in bold type represent ex-type specimens. CBS, Centraalbureau voor Schimmecultures, Utrecht, The Netherlands; CMW, Culture Collection of the Forestry and Agricultural Biotechnology Institute, University of Pretoria, Pretoria, South Africa; ATCC, American Type Culture Collection, Virginia, USA; MFLUCC, Mae Fah Luang University Culture Collection, Chiang Rai, Thailand.; CERC, Culture collection of China Eucalypt Research Centre, Zhanjiang, Guangdong Province, China. CBS 118718 (Tiarosporella graminis) was added as an outgroup.

${ }^{y}$ Sequences in italics were generated in this study. ITS, internal transcribed spacer (ITS1-5.8S-ITS2); BT, $\beta$-tubulin; TEF, translation elongation factor 1- $\alpha$.

${ }^{\mathrm{z}}$ Isolates used for morphological characterization and pathogenicity tests. 
scattered, spherical, dark-brown pycnidia, 135.5 to $305.5 \mu \mathrm{m}$ in diameter $(n=20)$, formed on the surface of PDA plates 20 days after incubation (Fig. 2D). Conidia from pycnidia were hyaline, thin, spindle or fusiform, and unicellular, with sizes of 13.55 to $28.32 \times 4.17$ to $8.8 \mu \mathrm{m}$ and a mean length/width ratio of $3.34(n=80)$ (Fig. 2C). These morphological characters indicated that those isolates belonged to the genus Botryosphaeria (Slippers et al. 2004). Additionally, conidia incubated from different isolates were compared with descriptions of those of the Botryosphaeria species described in the literature (Table 3). The statistics showed that conidia incubated in this study were most similar to those of $B$. dothidea isolated in China and different from those of other species of Botryosphaeria.

Phylogenetic analysis of isolates. To verify the identification based on morphological characteristics, fragments of the ITS and BT and TEF genes were amplified from all 89 isolates (Tables 1 and 2). The sizes of ITS, BT, and TEF PCR products of those isolates were 507 to $575 \mathrm{bp}, 385$ to $438 \mathrm{bp}$, and 223 to $287 \mathrm{bp}$ in length, respectively. Multiple sequence alignments showed that all of the strains shared 99.8 to $100 \%, 99.75$ to $100 \%$, and 99.57 to $100 \%$ nucleotide sequence similarities for the ITS region, BT, and TEF genes, respectively.

Eleven representative isolates (ZB-8, ZB-15, ZB-23, ZB-27, ZB33, ZB-36, ZB-45, ZB-56, ZB-59, ZB-69, and ZB-77) were used for phylogenetic analysis (Table 2). Alignment of the three-locus dataset (ITS + BT + TEF) included 40 taxa, resulting in a 1,075character dataset in which 222 characters were parsimony informative, 112 characters were parsimony uninformative, and 741 characters were constant. MP analysis produced 10 equally mostparsimonious trees of 354 steps, with a CI and RI of 0.803448 and 0.933798 , respectively.
ML and MP analyses based on the combined sequences revealed that all representative isolates recovered from symptomatic $C$. paliurus stem cankers in China showed $\geq 99 \%$ similarity to the $B$. dothidea isolates reported previously but were significantly different from other species of Botryosphaeria (Fig. 3).

Pathogenicity Tests. Pathogenicity test on detached branches. A necrotic and often sunken lesion with discoloration of the bark, similar to the typical disease symptoms in Baima, occurred on detached C. paliurus branches 10 days after inoculation (Fig. 4A to C). At 2 weeks after inoculation, mean disease incidence among the test isolates ranged from 73.3 to $90.0 \%$. When results of the mean vascular discoloration lengths were combined, ZB-23 was clearly the most virulent isolate, with significantly longer vascular discoloration than ZB-8 and ZB-69, and there was no significant difference between isolate ZB-8 and ZB-69 according to Tukey's honestly significant difference test $(P=0.05)$ (Table 4$)$. Additionally, pycnidia, ranging from 81.83 to $319.39 \mu \mathrm{m}$ in diameter, were formed on the outer bark surface of the inoculated withered branch segments (Fig. 2) 30 days after inoculation.

Pathogenicity test on intact plants. The first symptoms, similar to those observed in detached shoots, were observed 20 days after inoculation with mycelium plugs (Fig. $4 \mathrm{H}$ to J). However, lesion symptoms did not develop further when callus formed around the sunken area (Fig. $4 \mathrm{H}$ to J). At $45 \mathrm{dpi}$, the disease incidence showed significant differences $(P<0.05)$ among the isolates tested, ranging from 66.7 to $83.3 \%$. The test isolates significantly differed $(P<0.05)$ in the extent of vascular discoloration. Similar to the results on detached branches, isolate ZB-23 was the most virulent, followed by isolates ZB-8 and ZB-69 (Table 4). However, pycnidia were not formed on the bark of the plants, even after 90 days.
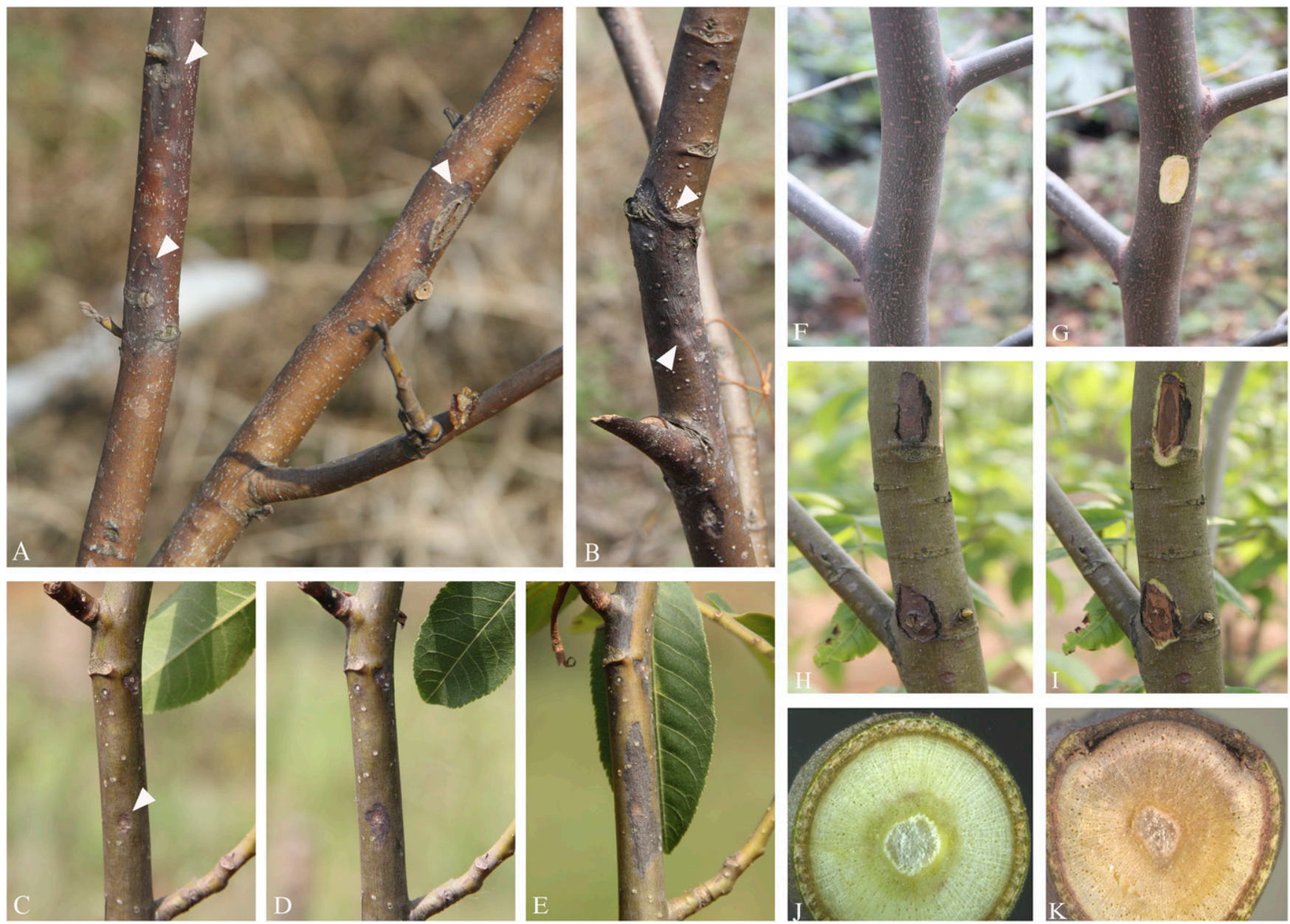

Fig. 1. Disease symptoms of cankers on Cyclocarya paliurus trees in nursery. A, Sunken cankers near wounds on, trunks in early spring, with canker expanding (indicated by arrow). B, Cankers expand and coalesce, girdling the branch. C to E, Progress of the canker's enlargement in nature. F and $\mathbf{G}$, Healthy branches. $\mathbf{H}$ and I, Cankers with bark cracking on branch. $\mathbf{J}$ and $\mathbf{K}$, Transverse section of $\mathbf{J}$, healthy branch and $\mathbf{K}$, infected branch. 
Pathogenicity of conidia collected from pycnidia. Typical disease symptoms were observed after 12 days on detached branches and 30 days on intact plants, respectively, following inoculation with conidia of ZB-23. However, at 2 weeks on detached branches and 45 days on intact plants, respectively, after inoculation, both disease incidence and mean lesion lengths were significantly $(P<0.05)$ less than those in branches inoculated with mycelium plugs (Fig. 4 and Table 4). Pycnidia were formed on the surface of
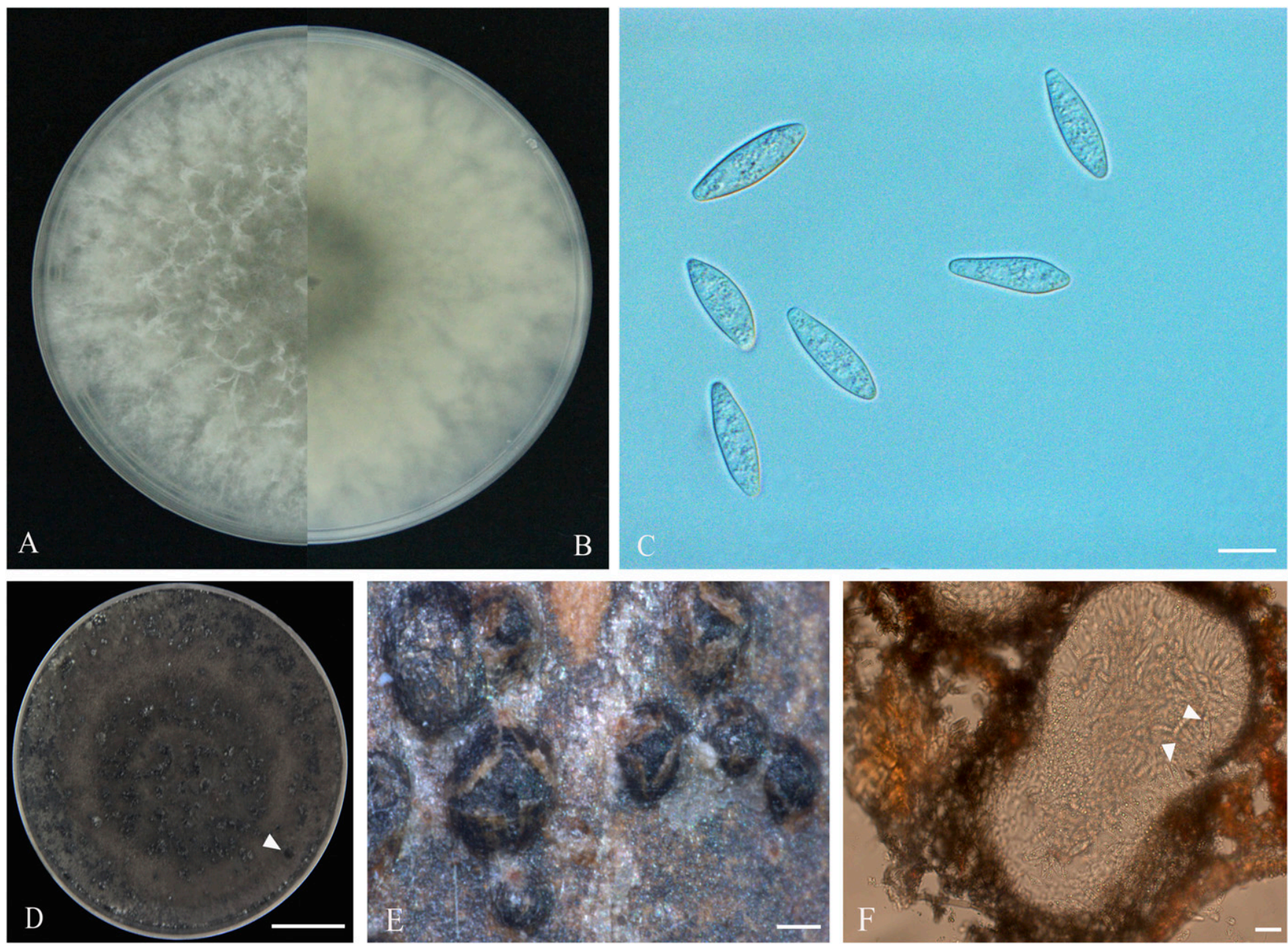

Fig. 2. Morphological characters of colonies, conidia, and pycnidia of Botryosphaeria dothidea. $\mathbf{A}$ and B, Top and reverse view of a B. dothidea colony. C, Conidia (bar $=10 \mu \mathrm{m}$ ). Pycnidia were produced on the surface of $\mathbf{D}$, colonies (indicated by arrow) and $\mathbf{E}$, inoculated branches $(\mathbf{D}$, bar $=2 \mathrm{~cm} ; \mathbf{E}$, bar $=100 \mu \mathrm{m})$. $F$, Transverse section of pycnidia with many conidia (indicated by arrows; bar $=20 \mu \mathrm{m}$ ).

Table 3. Comparison of conidial measurements of Botryosphaeria dothidea isolated from Cyclocarya paliurus against previously described Botryosphaeria spp.

\begin{tabular}{|c|c|c|c|c|c|c|}
\hline Species & Isolate $^{w}$ & Location & Conidial size $(\mu \mathrm{m})(\mathbf{L} \times \mathbf{W})^{\mathbf{x}}$ & Mean \pm SD $(\mu \mathrm{m})(L \times W)^{y}$ & $\mathbf{L} / \mathbf{W}^{\mathbf{z}}$ & Reference \\
\hline Botryosphaeria dothidea & ZB-8 & China & $(14.54-) 19.80-24.75(-28.24) \times(4.31-) 5.78-7.44(-7.98)$ & $22.27 \pm 2.47 \times 6.61 \pm 0.83$ & 3.37 & This study \\
\hline B. dothidea & ZB-23 & China & $(14.44-) 18.55-23.73(-27.98) \times(4.15-) 4.87-6.41(-7.56)$ & $21.14 \pm 2.59 \times 5.64 \pm 0.77$ & 3.75 & This study \\
\hline B. dothidea & ZB-69 & China & $(15.33-) 20.39-25.38(-29.22) \times(4.61-) 5.44-7.03(-7.78)$ & $22.89 \pm 2.50 \times 6.23 \pm 0.79$ & 3.67 & This study \\
\hline B. dothidea & CERC1972 & China & $(17.7-) 19.8-22.9(-25.1) \times(5.8-) 6.6-7.7(-8.3)$ & $21.4 \pm 1.5 \times 7.1 \pm 0.5$ & 3 & Li et al. 2016 \\
\hline B. dothidea & LNXC13-2 & China & $(21.3-) 25.0-30.0 \times(5.5-) 6.3-8.8$ & $25.7 \pm 1.5 \times 6.7 \pm 0.6$ & 3.8 & Xu et al. 2015 \\
\hline B. dothidea & ZH2211 & China & $(15.14-) 19.59-23.77(-25.59) \times(4.01-) 5.04-6.34(-7.19)$ & $21.68 \pm 2.09 \times 5.69 \pm 0.65$ & 3.86 & Zhai et al. 2014 \\
\hline B. dothidea & YZN1311 & China & $(14.32-) 18.12-23.82(-28.00) \times(4.38-) 5.53-7.23(-8.30)$ & $20.97 \pm 2.85 \times 6.38 \pm 0.85$ & 3.35 & Zhai et al. 2014 \\
\hline B. dothidea & Type & Switzerland & $(20-) 23-27(-30) \times 4-5(-6)$ & $24.7 \times 4.9$ & 5 & Slippers et al. 2004 \\
\hline Botryosphaeria ribis & Type & USA & $(15-) 16-19(-20) \times 5-6(-7)$ & $17.2 \times 5.5$ & 3.1 & Slippers et al. 2004 \\
\hline Botryosphaeria corticis & CBS119047 & USA & $(20.5-) 23.5-32.5(-34.5) \times(5.0-) 5.5-7(-7.5)$ & $28.9 \pm 3.4 \times 6.4 \pm 0.7$ & 4.5 & Phillips et al. 2013 \\
\hline Botryosphaeria ramosa & Type & $\begin{array}{l}\text { Western } \\
\text { Australia }\end{array}$ & $(11-) 12-15(-16) \times(4.7-) 5-6(-7)$ & & 2.3 & Phillips et al. 2013 \\
\hline Botryosphaeria scharifii & Type & Iran & $(11.5-) 13-17(-19) \times 4-6.5$ & $15.4 \pm 1.4 \times 5.2 \pm 0.5$ & 2.7 & Phillips et al. 2013 \\
\hline Botryosphaeria parva & DL2411 & China & $(11.26-) 12.96-15.66(-16.85) \times(5.11-) 5.91-7.33(-8.38)$ & $14.31 \pm 1.35 \times 6.62 \pm 0.71$ & 2.19 & Zhai et al. 2014 \\
\hline Botryosphaeria obtusa & J5211 & China & $(12.10-) 17.84-23.24(-26.67) \times(8.02-) 9.96-12.56(-14.61)$ & $20.54 \pm 2.70 \times 11.26 \pm 1.30$ & 1.85 & Zhai et al. 2014 \\
\hline Botryosphaeria rhodina & ZHn411 & China & $(17.12-) 23.17-28.41(-31.7) \times(11.41-) 13.39-16.51(-18.45)$ & $25.79 \pm 2.62 \times 14.95 \pm 1.56$ & 1.74 & Zhai et al. 2014 \\
\hline $\begin{array}{l}\text { Botryosphaeria } \\
\text { auasmontanum }\end{array}$ & Type & Namibia & $(8.1-) 8.8-11.3(-13) \times(2.5-) 2.9-3.9(-5)$ & $10.1 \times 3.4$ & 3 & Slippers et al. 2014 \\
\hline
\end{tabular}

\footnotetext{
w Isolates used for measurements are ex-type or from samples that have been matched to the type material of the species.

x $\mathrm{L} \times \mathrm{W}=$ length by width; minimum-(average-standard deviation [SD])-(average \pm SD)-maximum.

y $\mathrm{L} \times \mathrm{W}=$ length by width.

z $\mathrm{L} / \mathrm{W}=$ average length/average width.
} 
the detached branches after 30 days but not on intact plants at 90 dpi.

In summary, all tested isolates induced the canker lesions on wounded, detached branch segments and on branches of the intact plants, where isolate ZB-23 was the most virulent (Fig. 4 and Table 4). Although conidia could also cause typical symptoms, the virulence was weaker than that of mycelium plugs, probably because of environmental factors. $B$. dothidea was reisolated from the inoculated branches and verified to be the original isolate used for the inoculations. C. paliurus trees or detached branches inoculated with noncolonized PDA or sterile water showed no symptoms (Fig. 4A, E, G, and $\mathrm{K}$ ), and the small necrotic lesions observed around the inoculation sites represented reactions of the wood to wounding, because none of the $B$. dothidea isolates could be reisolated from them, thus completing Koch's postulate.

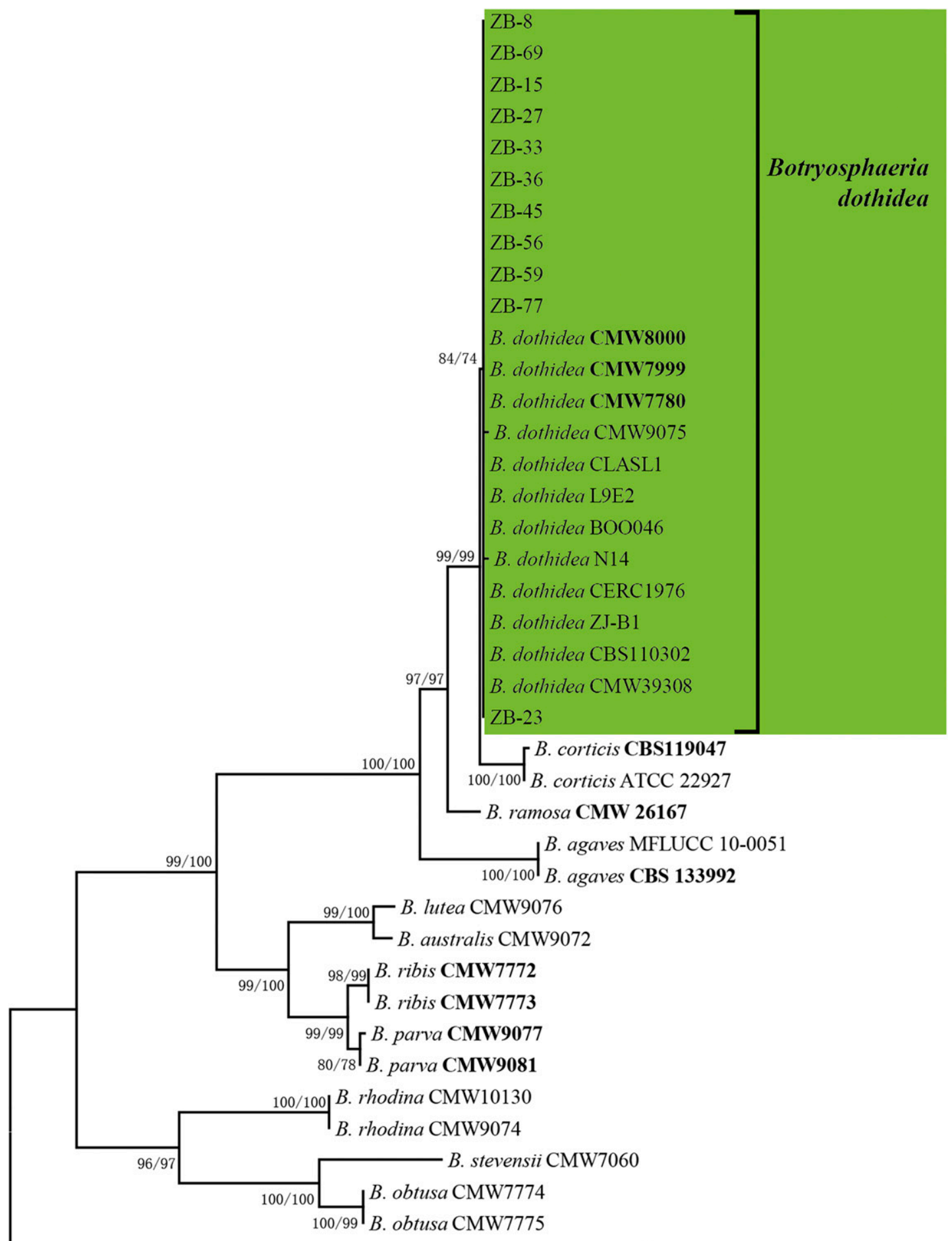

Tiarosporella graminis CBS 118718

Fig. 3. Single most likely tree (in likelihood -3102.7822) obtained from the combined analysis of the internal transcribed spacer, $\beta$-tubulin, and translation elongation factor 1- $\alpha$ sequences from species of the genera Botryosphaeria. Numbers representing maximum parsimony and maximum likelihood bootstrap values (>60\%) are shown at nodes. Ex-type specimens are highlighted in bold type. Bar represents the expected number of substitutions per site. Tiarosporella graminis was included as an outgroup. 


\section{Discussion}

Pathogenicity tests in our study demonstrated that isolates of $B$. dothidea were able to cause stem canker symptoms both on detached branches and on potted plants of $C$. paliurus. Although there was variation in pathogenicity among strains of $B$. dothidea, it was probably because of the virulence of isolates or different weather conditions and other environmental factors that cannot be controlled in nature. Our results indicated that the causal agent of stem canker disease of $C$. paliurus is $B$. dothidea. The putative adaptation of $B$. dothidea to a new plant host might have been influenced by unknown factors, such as climate change (Wakelin et al. 2018; Zhan et al. 2018) and gene evolution (Dong et al. 2014; Gaulin et al. 2018), which must be further studied.
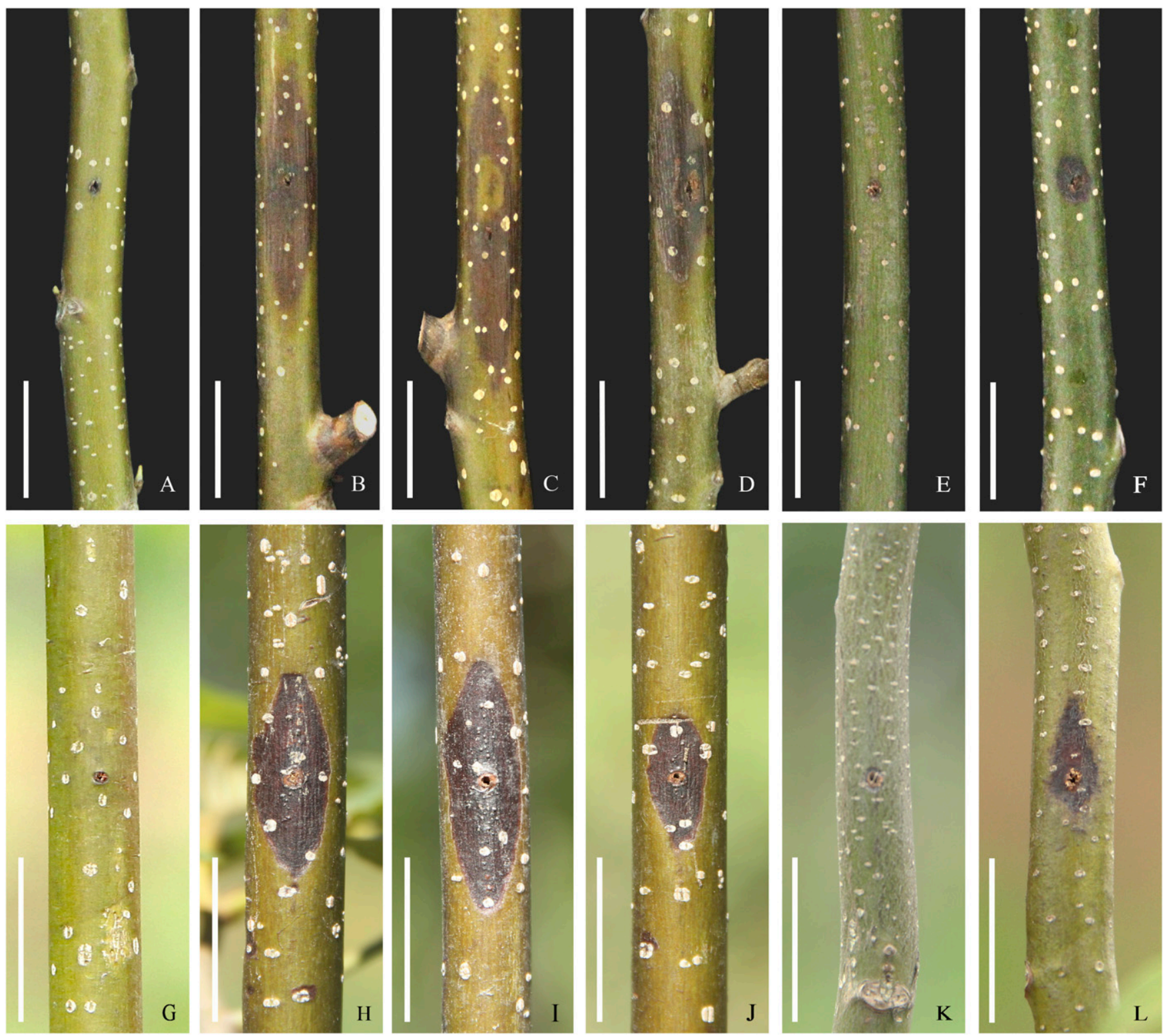

Fig. 4. Disease symptoms on detached Cyclocarya paliurus branches and potted plants 2 weeks and 45 days, respectively, after inoculation with mycelial plugs or conidia of the Botryosphaeria dothidea isolates. Lesions on detached 2-year-old shoots after inoculation with mycelial plugs of the A, control; B, isolate ZB-8; C, isolate ZB-23; and D, isolate ZB69; and conidial suspensions of the $\mathbf{E}$, control and $\mathbf{F}$, isolate ZB-23. Lesions on 3-year-old potted plants under natural conditions after inoculation with mycelial plugs of the $\mathbf{G}$, control; H, isolate ZB-8; I, isolate ZB-23; and J, isolate ZB-69; and conidial suspensions of the K, control and L, isolate ZB-23.

Table 4. Disease incidences and symptoms on Cyclocarya paliurus detached branches and potted plants inoculated with isolates of Botryosphaeria dothidea ${ }^{\mathrm{z}}$

\begin{tabular}{|c|c|c|c|c|c|c|c|c|}
\hline \multirow[b]{3}{*}{ Isolates } & \multicolumn{4}{|c|}{ Detached branches } & \multicolumn{4}{|c|}{ Potted plants } \\
\hline & \multicolumn{2}{|c|}{ Inoculated with mycelium plugs } & \multicolumn{2}{|c|}{ Inoculated with conidia } & \multicolumn{2}{|c|}{ Inoculated with mycelium plugs } & \multicolumn{2}{|c|}{ Inoculated with conidia } \\
\hline & $\begin{array}{l}\text { Lesion length } \\
\quad(\mathrm{mm})\end{array}$ & $\begin{array}{c}\text { Incidence } \\
(\%)\end{array}$ & $\begin{array}{l}\text { Lesion length } \\
\quad(\mathrm{mm})\end{array}$ & $\begin{array}{c}\text { Incidence } \\
(\%)\end{array}$ & $\begin{array}{l}\text { Lesion length } \\
\quad(\mathrm{mm})\end{array}$ & $\begin{array}{c}\text { Incidence } \\
(\%)\end{array}$ & $\begin{array}{l}\text { Lesion length } \\
\quad(\mathrm{mm})\end{array}$ & $\begin{array}{c}\text { Incidence } \\
(\%)\end{array}$ \\
\hline ZB-8 & $40.11 \pm 1.90 \mathrm{~b}$ & $80.00 \pm 5.16$ & - & - & $26.49 \pm 1.13 b$ & $73.33 \pm 6.67$ & - & - \\
\hline ZB-23 & $58.47 \pm 1.57 \mathrm{a}$ & $90.00 \pm 4.47$ & $13.07 \pm 0.74 \mathrm{c}$ & $60.00 \pm 5.16$ & $35.47 \pm 1.09 \mathrm{a}$ & $83.33 \pm 6.15$ & $14.98 \pm 0.93 \mathrm{c}$ & $40.00 \pm 5.16$ \\
\hline ZB-69 & $35.42 \pm 2.30 \mathrm{~b}$ & $73.33 \pm 6.67$ & - & - & $17.21 \pm 0.88 \mathrm{c}$ & $66.67 \pm 8.43$ & - & - \\
\hline
\end{tabular}

${ }^{\mathrm{z}}$ A dash (-) indicates not tested. Values are means ( \pm standard error) of two repeated experiments. Means with different letters indicate mean lesion lengths that are significantly different $(P=0.05)$. Data was calculated from the disease incidence of 12 to 27 inoculation sites on shoots of intact plants or detached branches. 
In a previous study, some species in the family Botryosphaeriaceae could overwinter as pycnidia on blighted shoots from the previous year (Thomidis et al. 2011). The primary inoculum sources in the present year were the conidia from the overwintered pycnidia, and new pycnidia could produce conidia as secondary inoculum sources. In our study, numerous pycnidia were found on the surface of inoculated dead branches, and pathogenicity tests of conidia from these pycnidia demonstrated that these conidia could also cause $C$. paliurus stem canker, although the virulence was lower than that of mycelium plug, which may be influenced by concentration, duration of the conidial suspension, or environmental factors. In general, these results indicated that symptomatic branches infected by $B$. dothidea may play an important part in the infection cycle of $C$. paliurus stem canker. Accordingly, based on our results, we speculate that $B$. dothidea infects wounds or other infection sites on $C$. paliurus branches by means of conidia released from pycnidia during the growing season; however, further investigation of this question is needed.

B. dothidea, a well-known latent pathogen (Jami et al. 2013; Slippers and Wingfield 2007), has been reported from numerous hosts with a worldwide distribution (Marsberg et al. 2017; Tang et al. 2012; Zhou et al. 2015). B. dothidea is considered to be a stressassociated phytopathogen (Marsberg et al. 2017; Slippers and Wingfield 2007; Zhang et al. 2013). When some abiotic stresses such as physical damage, drought, and unsuitable growing conditions occur, species in the Botryosphaeriaceae family can cause those observed symptoms on different hosts and do not show any host specificity (Jami et al. 2015; Marsberg et al. 2017; Slippers and Wingfield 2007; Zhang et al. 2013). Infection of native and nonnative trees by $B$. dothidea has been recorded in numerous studies (Jami et al. 2013; Marsberg et al. 2017; Mohali et al. 2007; Pavlic et al. 2007; Slippers et al. 2009). The low host specificity of $B$. dothidea increases the risk that it will acquire new hosts once introduced into a new region (Marsberg et al. 2017).

This study represents the first comprehensive effort to characterize Botryosphaeriaceae species from symptomatic $C$. paliurus trees affected by stem canker in China to date. In this study, we examined culture morphology, pycnidia, and conidia morphology of C. paliurus canker isolates to support identification of the species, demonstrating that these isolates belong to the genus Botryosphaeria. DNA sequence comparisons of the ITS region, translation elongation factor $1-\alpha$, and $\beta$-tubulin genes have been used recently to credibly and effectively identify species of Botryosphaeria (Liu et al. 2012; Lynch et al. 2013; McDonald and Eskalen 2011). Combining results of conidial measurements and phylogenetic analyses of the nuclear DNA-ITS region, translation elongation factor $1-\alpha$, and $\beta$-tubulin genes, isolates from $C$. paliurus canker tissues were compared with Botryosphaeria spp. reference isolates from different hosts and geographic locations (Tables 2 and 3), which indicated that all $C$. paliurus canker isolates could be identified as B. dothidea. Although there may be cryptic species, further genetic analysis using other genes may help to resolve such intraspecies or interspecies variation (Chen et al. 2014).

\section{Literature Cited}

Barr, M. E. 1972. Preliminary studies on the Dothideales in temperate North America. Contrib. Univ. Mich. Herb. 9:523-638.

Burgess, T. I., Barber, P. A., and Hardy, G. 2005. Botryosphaeria spp. associated with eucalypts in Western Australia, including the description of Fusicoccum macroclavatum sp. nov. Australas. Plant Pathol. 34:557-567.

Carbone, I., and Linda, M. K. 1999. A method for designing primer sets for speciation studies in filamentous ascomycetes. Mycologia 91:553-556.

Chen, S., Morgan, D. P., Hasey, J. K., Anderson, K., and Michailides, T. J. 2014. Phylogeny, morphology, distribution, and pathogenicity of Botryosphaeriaceae and Diaporthaceae from English walnut in California. Plant Dis. 98:636-652.

Damm, U., Mostert, L., Crous, P. W., and Fourie, P. H. 2008. Novel Phaeoacremonium species associated with necrotic wood of Prunus trees. Persoonia 20:87-102.

Dong, C., Xie, M., Li, C., and Nie, S., 2007. AGFD 154-In vitro antioxidant activity of different extracts of Cyclocarya paliurus (Batal.) Iljinsk. Abstract of papers of the American Chemical Society 234.

Dong, S., Stam, R., Cano, L. M., Song, J., Sklenar, J., Yoshida, K., Bozkurt, T. O., Oliva, R., Liu, Z., Tian, M., Win, J., Banfield, M. J., Jones, A. M. E., van der
Hoorn, R. A. L., and Kamoun, S. 2014. Effector specialization in a lineage of the Irish potato famine pathogen. Sci. 343:552-555.

Gaulin, E., Pel, M. J. C., Camborde, L., San-Clemente, H., Courbier, S., Dupouy, M., Lengelle, J., Veyssiere, M., Le Ru, A., Grandjean, F., Cordaux, R., Moumen, B., Gilbert, C., Cano, L. M., Aury, J., Guy, J., Wincker, P., Bouchez, O., Klopp, C., and Dumas, B. 2018. Genomics analysis of Aphanomyces spp. identifies a new class of oomycete effector associated with host adaptation. BMC Biol.. 16:552.

Glass, N. L., and Donaldson, G. C. 1995. Development of primer sets designed for use with the PCR to amplify conserved genes from filamentous ascomycetes. Appl. Environ. Microbiol. 61:1323-1330.

Jami, F., Slippers, B., Wingfield, M. J., and Gryzenhout, M. 2013. Greater Botryosphaeriaceae diversity in healthy than associated diseased Acacia karroo tree tissues. Australas. Plant Pathol. 42:421-430.

Jami, F., Slippers, B., Wingfield, M. J., Loots, M. T., and Gryzenhout, M. 2015. Temporal and spatial variation of Botryosphaeriaceae associated with Acacia karroo in South Africa. Fungal Ecol. 15:51-62.

Kurihara, H., Asami, S., Shibata, H., Fukami, H., and Tanaka, T. 2003a Hypolipemic effect of Cyclocarya paliurus (Batal) Iljinskaja in lipid-loaded mice. Biol. Pharm. Bull. 26:383-385.

Kurihara, H., Fukami, H., Kusumoto, A., Toyoda, Y., Shibata, H., Matsui, Y., Asami, S., and Tanaka, T. 2003b. Hypoglycemic action of Cyclocarya paliurus (Batal.) Iljinskaja in normal and diabetic mice. Biosci. Biotechnol. Biochem. 67:877-880.

Li, G. Q., Liu, F. F., Li, J. Q., Liu, Q. L., and Chen, S. F. 2016. Characterization of Botryosphaeria dothidea and Lasiodiplodia pseudotheobromae from English Walnut in China. J. Phytopathol. 164:348-353.

Li, L., Xie, M. Y., Sun, Z. H., Wu, X. H., Sun, D. H., and Wang, X. R. 2000. The study on the element transference characteristics and element speciation in the extract of Cyclocarya paliurus (Batal.) Iljinskaja leaves. Chem. J. Chin. Univ. 21:707-709.

Li, M., He, J., Ding, L., Kang, J., Zhang, Q., and Zheng, Q. 2007. Single spore strains without producing fruit body isolated from Cordyceps militaris and their RAPD analysis. Southwest China. J. Agric. Sci. 20:547-550.

Liu, J., Phookamsak, R., Doilom, M., Wikee, S., Li, Y., Ariyawansha, H., Boonmee, S., Chomnunti, P., Dai, D., Bhat, J. D., Romero, A. I., Zhuang, W., Monkai, J., Jones, E. B. G., Chukeatirote, E., Ko, T. W. K., Zhao, Y., Wang, Y., and Hyde, K. D. 2012. Towards a natural classification of Botryosphaeriales. Fungal Divers. 57:149-210.

Lynch, S. C., Eskalen, A., Zambino, P. J., Mayorquin, J. S., and Wang, D. H. 2013 Identification and pathogenicity of Botryosphaeriaceae species associated with coast live oak (Quercus agrifolia) decline in southern California. Mycologia 105:125-140.

Marincowitz, S., Groenewald, J. Z., Wingfield, M. J., and Crous, P. W. 2008 Species of Botryosphaeriaceae occurring on Proteaceae. Persoonia 21 111-118.

Marsberg, A., Kemler, M., Jami, F., Nagel, J. H., Postma-Smidt, A., Naidoo, S., Wingfield, M. J., Crous, P. W., Spatafora, J. W., Hesse, C. N., Robbertse, B. and Slippers, B. 2017. Botryosphaeria dothidea: a latent pathogen of global importance to woody plant health. Mol. Plant Pathol. 18:477-488.

McDonald, V., and Eskalen, A. 2011. Botryosphaeriaceae species associated with avocado branch cankers in California. Plant Dis. 95:1465-1473.

Mohali, S. R., Slippers, B., and Wingfield, M. J. 2007. Identification of Botryosphaeriaceae from Eucalyptus, Acacia and Pinus in Venezuela. Fungal Divers. 25:103-125

Moral, J., Agusti-Brisach, C., Perez-Rodriguez, M., Xavier, C., Raya, M. C., Rhouma, A., and Trapero, A. 2017. Identification of fungal species associated with branch dieback of olive and resistance of table cultivars to Neofusicoccum mediterraneum and Botryosphaeria dothidea. Plant Dis. 101:306-316.

Pavlic, D., Slippers, B., Coutinho, T. A., and Wingfield, M. J. 2007. Botryosphaeriaceae occurring on native Syzygium cordatum in South Africa and their potential threat to Eucalyptus. Plant Pathol. 56:624-636.

Pavlic, D., Slippers, B., Coutinho, T. A., and Wingfield, M. J. 2009. Multiple gene genealogies and phenotypic data reveal cryptic species of the Botryosphaeriaceae: A case study on the Neofusicoccum parvum/N. ribis complex. Mol. Phylogenet. Evol. 51:259-268.

Pérez, C. A., Wingfield, M. J., Slippers, B., Altier, N. A., and Blanchette, R. A. 2010. Endophytic and canker-associated Botryosphaeriaceae occurring on non-native Eucalyptus and native Myrtaceae trees in Uruguay. Fungal Divers. 41:53-69.

Phillips, A. J. L., Alves, A., Abdollahzadeh, J., Slippers, B., Wingfield, M. J., Groenewald, J. Z., and Crous, P. W. 2013. The Botryosphaeriaceae: genera and species known from culture. Stud. Mycol. 76:51-167.

Salemi, M., and Vandamme, A. M. 2003. The Phylogenetic Handbook: A Practical Approach to DNA and Protein Phylogeny. Cambridge University Press, Cambridge, UK.

Slippers, B., Burgess, T., Pavlic, D., Ahumada, R., Maleme, H., Mohali, S., Rodas, C., and Wingfield, M. J. 2009. A diverse assemblage of Botryosphaeriaceae infect Eucalyptus in native and non-native environments. South. For. 71: 101-110.

Slippers, B., Crous, P. W., Denman, S., Coutinho, T. A., Wingfield, B. D., and Wingfield, M. J. 2004. Combined multiple gene genealogies and phenotypic characters differentiate several species previously identified as Botryosphaeria dothidea. Mycologia 96:83-101. 
Slippers, B., Johnson, G. I., Crous, P. W., Coutinho, T. A., Wingfield, B. D., and Wingfield, M. J. 2005. Phylogenetic and morphological re-evaluation of the Botryosphaeria species causing diseases of Mangifera indica. Mycologia 97: 99-110.

Slippers, B., Roux, J., Wingfield, M. J., van der Walt, F. J. J., Jami, F., Mehl, J. W. M., and Marais, G. J. 2014. Confronting the constraints of morphological taxonomy in the Botryosphaeriales. Persoonia 33:155-168.

Slippers, B., and Wingfield, M. J. 2007. Botryosphaeriaceae as endophytes and latent pathogens of woody plants: diversity, ecology and impact. Fungal Biol. Rev. 21:90-106.

Tamura, K., Stecher, G., Peterson, D., Filipski, A., and Kumar, S. 2013. MEGA6: Molecular Evolutionary Genetics Analysis Version 6.0. Mol. Biol. Evol. 30: 2725-2729.

Tang, W., Ding, Z., Zhou, Z. Q., Wang, Y. Z., and Guo, L. Y. 2012. Phylogenetic and pathogenic analyses show that the causal agent of apple ring rot in China is Botryosphaeria dothidea. Plant Dis. 96:486-496.

Thomidis, T., Michailides, T. J., and Exadaktylou, E. 2011. Neofusicoccum parvum associated with fruit rot and shoot blight of peaches in Greece. Eur. J. Plant Pathol. 131:661-668.

Thompson, J. D., Gibson, T. J., Plewniak, F., Jeanmougin, F., and Higgins, D. G. 1997. The CLUSTAL_X windows interface: flexible strategies for multiple sequence alignment aided by quality analysis tools. Nucleic Acids Res. 25: 4876-4882.

van Niekerk, J. M., Crous, P. W., Groenewald, J. Z., Fourie, P. H., and Halleen, F. 2004. DNA phylogeny, morphology and pathogenicity of Botryosphaeria species on grapevines. Mycologia 96:781-798.

Wakelin, S. A., Gomez-Gallego, M., Jones, E., Smaill, S., Lear, G., and Lambie, S. 2018. Climate change induced drought impacts on plant diseases in New Zealand. Australas. Plant Pathol. 47:101-114.

Wang, Z. J., Xie, J. H., Yang, Y. J., Zhang, F., Wang, S. N., Wu, T., Shen, M. Y., and Xie, M. Y. 2017. Sulfated Cyclocarya paliurus polysaccharides markedly attenuates inflammation and oxidative damage in lipopolysaccharide-treated macrophage cells and mice. Sci. Rep.. 7:40402.
White, T. J., Bruns, T., Lee, S., and Taylor, J. W. 1990. Amplification and direct sequencing of fungal ribosomal RNA genes for phylogenetics. Pages 315-322 in: PCR Protocols: A Guide to Methods and Applications. M. A. Innis, D. H Gelfand, J. J. Sninsky, and T. J. White, eds. Academic Press, New York.

Xie, J., Shen, M., Xie, M., Nie, S., Chen, Y., Li, C., Huang, D., and Wang, Y. 2012. Ultrasonic-assisted extraction, antimicrobial and antioxidant activities of Cyclocarya paliurus (Batal.) Iljinskaja polysaccharides. Carbohydr. Polym. 89:177-184.

Xie, J., Xie, M., Nie, S., Shen, M., Wang, Y., and Li, C. 2010. Isolation, chemical composition and antioxidant activities of a water-soluble polysaccharide from Cyclocarya paliurus (Batal.). Iljinskaja. Food Chem. 119:1626-1632.

Xie, M. Y., and Li, L. 2001. Review in studies on chemical constituents and bioactivities of Cyclocarya paliurus. Chin. Tradit. Herbal Drugs 32:365-366.

Xie, M. Y., Li, L., Nie, S. P., Wang, X. R., and Lee, F. 2006. Determination of speciation of elements related to blood sugar in bioactive extracts from Cyclocarya paliurus leaves by FIA-ICP-MS. Eur. Food Res. Technol. 223 202-209.

Xu, C., Zhang, H., Zhou, Z., Hu, T., Wang, S., Wang, Y., and Cao, K. 2015 Identification and distribution of Botryosphaeriaceae species associated with blueberry stem blight in China. Eur. J. Plant Pathol. 143:737-752.

Zhai, L., Zhang, M., Lv, G., Chen, X., Jia, N., Hong, N., and Wang, G. 2014. Biological and molecular characterization of four Botryosphaeria species isolated from pear plants showing stem wart and stem canker in China. Plant Dis. 98:716-726.

Zhan, J., Ericson, L., and Burdon, J. J. 2018. Climate change accelerates local disease extinction rates in a long-term wild host-pathogen association. Glob. Change Biol. 24:3526-3536.

Zhang, Z. X., Deng, D. F., Qi, W. J., Fan, S. S., Cao, Y., Huang, J. G., and Liu, Z. Y 2013. Botryosphaeria dothidea, the causal agent of a new canker disease of Tatarian dogwood (Cornus alba) in China. Australas. Plant Pathol. 42:113-119.

Zhou, Y., Gong, G., Cui, Y., Zhang, D., Chang, X., Hu, R., Liu, N., and Sun, X 2015. Identification of Botryosphaeriaceae species causing kiwifruit rot in Sichuan Province, China. Plant Dis. 99:699-708. 